\title{
DESEMPENHO DE PERUS FÊMEAS DE 29 A 126 DIAS DE IDADE, ALIMENTADOS COM RAÇÕES CONTENDO REDUÇÃO ENERGÉTICA E XILANASE
}

\author{
(Performance of female turkeys in the 29 to 126 days of age, fed with diets \\ containing energetic reduction and xylanase)
}

Rafael Fernando Sens ${ }^{1}$, Leopoldo Malcorra de Almeida ${ }^{1}$, Kariny Fonseca da Silva ${ }^{1}$, Marley Conceição dos Santos ${ }^{1}$, Josiane Carla Panisson ${ }^{1}$, Geovani Costa Senger ${ }^{1}$, Alex Maiorka ${ }^{1}$

${ }^{1}$ Universidade Federal do Paraná, Curitiba, Paraná, Brasil

Corresponding author: almeidamleopoldo@gmail.com

RESUMO: O trigo no Brasil é um ingrediente pouco utilizado em rações devido ao seu alto custo de produção. Na parede de cereais como o trigo, há a presença de polissacarídeos não amiláceos (PNAs), e esses compostos influenciam negativamente o aproveitamento da energia, aumentando a retenção de água no intestino e a viscosidade do conteúdo intestinal consequentemente. A enzima xilanase atua rompendo as paredes celulares dos PNAs melhorando a digestibilidade dos nutrientes. $O$ objetivo com o presente estudo foi avaliar os efeitos da enzima xilanase sobre o desempenho de perus de corte dos 29 aos 126 dias. Foram utilizadas 360 aves, alojadas em baias móveis. As aves foram distribuídas em delineamento inteiramente casualizado, divididas em três tratamentos: dieta controle (T1), T1 com redução de 150 kcal (T2) e T2 com adição de xilanase na dose de $100 \mathrm{~g} / \mathrm{ton}$ (T3), cada tratamento com 8 repetições, cada uma com 15 aves. As varíaveis zootécnicas avaliadas foram consumo de ração, ganho de peso e conversão alimentar e os resultados foram submetidos à análise de variância. Verificou-se que a adição da enzima xilanase em dietas de perus formuladas à base de milho e farelo de soja não promoveu melhorias sobre o desempenho das aves $(P>0,05)$. Entretanto, os perus fêmeas alimentados com rações com trigo e enzima apresentaram menor CR e CA. Com o uso do nível de $150 \mathrm{Kcal}$ maior de energia nas dietas em todas as fases, o consumo de ração diminuiu significativamente $(P<0,05)$, o que refletiu positivamente na $C A$. $A$ adição da enzima xilanase e o incremento de energia não resultaram em diferenças significativas de ganho de peso $(P>0,05)$.

Palavras-chave: Fatores antinutricionais; enzimas; trigo.

ABSTRACT: The wheat in Brazil is a little-used ingredient in diets due to its high production cost. On the wall of cereals such as wheat, there is the presence of nonstarch polysaccharides (NSP), these compounds negatively influence the energy, increasing water retention in the intestine and, consequently, the viscosity of intestinal contents. The enzyme xylanase acts breaking the cell walls NSP, promoting a higher digestibility of nutrients. The objective with this study was to evaluate the effects of the enzyme xylanase on performance of turkeys cutting of 29 to 126 days. 360 birds were used line BUT 9, housed in movable pens. The birds were distributed in a completely randomized design, divided into three treatments: control diet (T1), T1 with a reduction of $150 \mathrm{kcal}$ (T2) and T2 with addition of xylanase at a dose of $100 \mathrm{~g} /$ ton (T3), each treatment with 8 repetitions, each with 15 birds. The birds were evaluated for feed intake, weight gain and feed conversion, 
and the results were submitted to analysis of variance. The results showed that the addition of the enzyme xylanase in diets of turkeys made from corn and soybean meal did not promote improvements on the performance of birds $(P>0.05)$. However, when the wheat is added to the diet decreasing the energy content, the action of the enzyme promotes a decrease in feed intake and improved feed conversion of poultry $(P<0.05)$. However, female turkeys fed with diets with wheat and enzyme showed lower CR and CA. With the use of the $150 \mathrm{Kcal}$ higher energy level in the diets in all phases, the feed intake decreased significantly $(P<0.05)$, which reflected positively in the CA. The addition of xylanase enzyme and the increase of energy did not result in significant differences in weight gain $(P>0.05)$.

Keywords: Antinutritional factors; enzymes; wheat. 


\section{INTRODUÇÃO}

A avicultura brasileira vem crescendo ao longo dos últimos anos, e a produção de perus também segue esta tendência, chegando a 173 mil toneladas em 2019 de acordo com a Associação Brasileira de Proteína Animal (ABPA, 2020). A alimentação se apresenta como o maior custo na produção destas aves, sendo que dietas de perus de corte têm como característica marcante a alta exigência proteica, especialmente na fase préinicial (1 a 21 dias). Por isso, é comum que 0 farelo de soja, ingrediente consagrado por seu alto valor proteico, seja utilizado em abundância para que estas exigências sejam atendidas.

No Brasil, o trigo costuma ser pouco utilizado em rações devido ao seu alto custo de aquisição. Na Europa e nos Estados Unidos, o trigo é utilizado como uma fonte importante de energia nas dietas para aves, podendo substituir o milho em até 100\% (Ward, 1995).

Annison e Choct (1991) citaram que a presença de polissacarídeos não amiláceos (PNAs) na parede de cereais como trigo, cevada, centeio e triticale influenciaram negativamente 0 aproveitamento da energia, elevando a retenção de água no intestino e, como consequência, a viscosidade do conteúdo intestinal. Segundo Bedford (1996), o aumento da viscosidade intestinal resulta em uma considerável redução na taxa de crescimento, piora na conversão alimentar e queda na energia metabolizável da ração.

Os animais monogástricos, em geral, não possuem a capacidade endógena de digerir os PNAs. Portanto, a utilização de enzimas exógenas se torna importante, pois estas hidrolisam os PNAs que podem ser potencialmente utilizados pelo animal, aumentando, por exemplo, a utilização de energia (Tavernari et al., 2008).

Persia et al. (2004) reportaram que a suplementação com enzimas exógenas pode melhorar a utilização de alimentos de perus em crescimento, principalmente em dietas a base de trigo. Santos Jr et al. (2004) concluíram que a suplementação com uma mistura comercial de enzimas contendo alto nível de xilanase reduziu os efeitos do alto conteúdo de PNAs do trigo em rações de perus.

As xilanases atuam proporcionando maiores valores de energia metabolizável aparente (EMA), devido, principalmente, à redução da viscosidade da digesta, resultando em maior ganho de peso e melhora na conversão alimentar em aves alimentadas com trigo (Hew et al., 1998; Wu e Ravidran, 2004; Tufarelli et al., 2007), ou com triticale (Poureza, 2007).

Para Silva e Smithard (2002) o uso de xilanase, associado a $\beta$-glucanases mostrou-se eficiente em melhorar 0 desempenho de aves alimentadas com dietas contendo ingredientes como trigo e cevada, e em promover o aumento da viscosidade, ou mesmo com milho e farelo de soja, considerados grãos que não promovem viscosidade (Mathlouthi et al., 2003).

O objetivo com o presente estudo foi avaliar o desempenho de perus de corte dos 29 aos 126 dias de idade alimentados com dietas contendo redução energética e adição de xilanase.

\section{MATERIAL E MÉTODOS}

Foram utilizadas 360 peruas, debicadas, da linhagem BUT 9. As aves foram criadas de um até 28 dias numa granja comercial. Os animais foram pesados e selecionados com peso entre $850 \mathrm{~g}$ e $950 \mathrm{~g}$.

Posteriormente, foram alojadas em 40 baias medindo $2 \mathrm{~m}$ de largura por 3 $\mathrm{m}$ de comprimento e $2,5 \mathrm{~m}$ de altura em um aviário comercial de $1.200 \mathrm{~m}^{2}$. A água e a ração foram fornecidas ad libitum, sendo que o bebedouro utilizado era do tipo pendular e a ração foi fornecida em comedouros do tipo 
tubular. Em cada baia havia um bebedouro e um comedouro.

Foram utilizados cerca de $20 \mathrm{~cm}$ de maravalha nova como cama. Foi utilizada luz natural, por aproximadamente 12 horas por dia. As aves mortas foram pesadas, assim como as aves doentes ou machucadas que foram eliminadas.

O delineamento experimental foi inteiramente casualizado com três tratamentos de oito repetições de 15 aves cada. Os tratamentos foram:

- Tratamento 1: dieta controle;

- Tratamento 2: dieta controle (T1) com redução de $150 \mathrm{kcal}$;

- Tratamento 3: dieta controle com redução de $150 \mathrm{kcal}$ (T2) e adição de xilanase (100 g/ton equivalente a $16.000 \mathrm{BXU} / \mathrm{kg}$ de enzima*)

*01 BXU é igual à atividade enzimática que libera $01 \mathrm{nmol}$ de açúcares redutores liberados como xilose por segundo a partir de uma solução padrão de xilano de Betula alba $\mathrm{L}$ a $50^{\circ} \mathrm{C}$ e $\mathrm{pH} 5,3$.

A enzima xilanase comercial utilizada foi a Econase XT 25, da empresa $A B$ Vista, intrinsicamente termorresistente. A matriz nutricional da enzima para perus é de 1.000.000 $\mathrm{kcal} / \mathrm{kg}$.

Os períodos analisados foram de 29 a 56 dias, de 57 a 84 dias, de 85 a 112 dias e dos 113 aos 126 dias de idade, além do período total de 29 até 126 dias de idade. As aves e as sobras de ração foram pesadas ao alojamento e ao fim de cada período, para a obtenção dos valores de consumo de ração, ganho de peso e conversão alimentar. $O$ consumo de ração foi dado pela diferença entre o ofertado e as sobras de alimento. O ganho de peso se deu pela pesagem das aves ao início e final de cada período sendo o resultado da diferença entre os dois valores. A conversão alimentar se deu pela divisão do consumo de ração pelo ganho de peso dos animais dentro dos períodos determinados.

As dietas experimentais nos diferentes períodos foram produzidas à base de milho e farelo de soja (Tabelas 1.1 a 1.4).

As rações foram produzidas em uma fábrica comercial. Os ingredientes foram pesados em duas balanças eletrônicas com capacidade de 2.000 e $1.000 \mathrm{~kg}$, as partículas finas foram separadas por uma peneira giratória com o diâmetro de $2 \mathrm{~mm}$. As partículas grosseiras foram moídas conjuntamente em moinhos de martelo, com peneiras em chapas de metal de $3,0 \mathrm{~mm}$ e 3,5 $\mathrm{mm}$. Os microingredientes foram pesados em balanças com capacidade de 20,50 e $100 \mathrm{~kg}$ e sofreram uma pré mistura antes de serem dosados no misturador. O óleo de soja degomado foi pesado em balanças com capacidade para $500 \mathrm{~kg}$ e a metionina hidroxianáloga em balanças com capacidade de $100 \mathrm{~kg}$.

A enzima foi pesada e adicionada diretamente no misturador, com capacidade para $10 \mathrm{~m}^{3}$ ou 6 ton de ração.

As dietas foram peletizadas em peletizadora VanAarsen, modelo compacta 900, com condicionador simples. O diâmetro da matriz possuía $900 \mathrm{~mm}$, furos de $4,0 \mathrm{~mm}$ e $75 \mathrm{~mm}$ de espessura com $10 \mathrm{~mm}$ de alívio. A temperatura de peletização foi de $75^{\circ} \mathrm{C}$. A ração posteriormente foi resfriada em resfriadores de contra-fluxo seguindo para uma peneira vibratória onde os finos voltavam para a peletizadora e os peletes íntegros seguiram para 0 ensaque.

Os resultados foram submetidos à análise de variância por meio da utilização do pacote estatístico SAEG (UFV, 2007) e, na presença de diferenças significativas, as médias foram comparadas pelo teste de Duncan a um nível de $5 \%$ de significância. 
Tabela 1.1 Composição das dietas experimentais no período de 29 a 56 dias.

\begin{tabular}{|c|c|c|c|}
\hline Ingredientes (\%) & T1 & T2 & T3 \\
\hline Milho & 46,17 & 45,61 & 45,61 \\
\hline Farelo de Soja $46 \%$ & 40,50 & 40,60 & 40,60 \\
\hline Farinha de Soja Micronizada & 4,00 & 4,00 & 4,00 \\
\hline Fosfato Monobicálcico 20\% & 2,40 & 2,40 & 2,40 \\
\hline Óleo de Soja Degomado & 3,60 & 2,10 & 2,10 \\
\hline Caulim & - & 1,90 & 1,89 \\
\hline Calcário Calcítico & 1,82 & 1,87 & 1,87 \\
\hline Metionina Hidróxi Análoga & 0,48 & 0,49 & 0,49 \\
\hline L-Lisina & 0,30 & 0,30 & 0,30 \\
\hline Sal Moído & 0,25 & 0,25 & 0,25 \\
\hline Bicarbonato de Sódio & 0,15 & 0,15 & 0,15 \\
\hline Premix Vitamínico Mineral & 0,20 & 0,20 & 0,20 \\
\hline L-Treonina $98,5 \%$ & 0,08 & 0,08 & 0,08 \\
\hline Cloreto de Colina $60 \%$ & 0,05 & 0,05 & 0,05 \\
\hline Xilanase & - & - & 0,01 \\
\hline Nutrientes & T1 & T2 & T3 \\
\hline Proteína Bruta & 24,00 & 24,00 & 24,00 \\
\hline $\mathrm{Ca}$ & 1,22 & 1,22 & 1,22 \\
\hline P Disponível & 0,79 & 0,79 & 0,79 \\
\hline Lisina (dig) & 1,40 & 1,40 & 1,40 \\
\hline Metionina (dig) & 0,56 & 0,56 & 0,56 \\
\hline Metionina + Cistina (dig) & 0,96 & 0,96 & 0,96 \\
\hline Treonina (dig) & 0,75 & 0,75 & 0,75 \\
\hline Triptofano (dig) & 0,20 & 0,20 & 0,20 \\
\hline Energia Metabolizável (kcal/kg) & 3.030 & 2.880 & 2.880 \\
\hline
\end{tabular}

${ }^{\mathrm{a}}$ Fornecido por kg de ração: Cobre $20 \mathrm{mg}$, Ferro $50 \mathrm{mg}$, Manganês $115 \mathrm{mg}$, Zinco $100 \mathrm{mg}$, lodo $2 \mathrm{mg}$, Selênio $0,35 \mathrm{mg} .{ }^{\mathrm{b}}$ Fornecido por kg de ração: Vitamina A 11.000 UI, Vitamina D3 $3.600 \mathrm{UI}$, Vitamina E $55 \mathrm{mg}$, Vitamina K $4 \mathrm{mg}$, Vitamina B1 $3 \mathrm{mg}$, Vitamina B2 $10 \mathrm{mg}$, Vitamina B6 $5 \mathrm{mg}$, Vitamina B12 0,016 mg, Ácido Fólico 2,5 mg, Ácido Nicotínico $56 \mathrm{mg}$, Ácido Pantotênico $20 \mathrm{mg}$, Biotina $0,32 \mathrm{mg}$, Antioxidante $88 \mathrm{mg}$. 
Tabela 1.2 Composição das dietas experimentais no período de 57 a 84 dias.

\begin{tabular}{|c|c|c|c|}
\hline Ingredientes & T1 & T2 & T3 \\
\hline Milho & 54,73 & 54,16 & 54,16 \\
\hline Farelo de Soja $46 \%$ & 31,80 & 31,80 & 31,80 \\
\hline Trigo & 5,00 & 5,00 & 5,00 \\
\hline Fosfato Monobicálcico 20\% & 1,66 & 1,66 & 1,66 \\
\hline Óleo de Soja Degomado & 4,10 & 2,60 & 2,60 \\
\hline Caulim & - & 2,00 & 1,90 \\
\hline Calcário Calcítico & 1,19 & 1,27 & 1,27 \\
\hline Metionina Hidróxi Análoga & 0,44 & 0,44 & 0,44 \\
\hline L-Lisina & 0,31 & 0,30 & 0,30 \\
\hline Sal Moído & 0,35 & 0,35 & 0,35 \\
\hline Premix Mineral $^{a}$ & 0,10 & 0,10 & 0,10 \\
\hline Premix Vitamínico ${ }^{b}$ & 0,15 & 0,15 & 0,15 \\
\hline L-Treonina $98,5 \%$ & 0,13 & 0,13 & 0,13 \\
\hline Cloreto de Colina $60 \%$ & 0,04 & 0,04 & 0,04 \\
\hline Xilanase & - & - & 0,01 \\
\hline Nutrientes & T1 & T2 & T3 \\
\hline Proteína Bruta & 21,00 & 21,00 & 21,00 \\
\hline $\mathrm{Ca}$ & 1,00 & 1,00 & 1,00 \\
\hline P Disponível & 0,50 & 0,50 & 0,50 \\
\hline Lisina (dig) & 1,15 & 1,15 & 1,15 \\
\hline Metionina (dig) & 0,56 & 0,56 & 0,56 \\
\hline Metionina + Cistina (dig) & 0,64 & 0,64 & 0,64 \\
\hline Treonina (dig) & 0,75 & 0,75 & 0,75 \\
\hline Triptofano (dig) & 0,20 & 0,20 & 0,20 \\
\hline Energia Metabolizável (kcal/kg) & 3.160 & 3.010 & 3.010 \\
\hline
\end{tabular}

${ }^{\mathrm{a}}$ Fornecido por kg de ração: Cobre $20 \mathrm{mg}$, Ferro $50 \mathrm{mg}$, Manganês $115 \mathrm{mg}$, Zinco $100 \mathrm{mg}$, lodo $2 \mathrm{mg}$, Selênio $0,35 \mathrm{mg}$. ${ }^{\mathrm{b}}$ Fornecido por $\mathrm{kg}$ de ração: Vitamina A $14.000 \mathrm{UI}$, Vitamina D343.500 UI, Vitamina E $70 \mathrm{mg}$, Vitamina K $5 \mathrm{mg}$, Vitamina B1 $4 \mathrm{mg}$, Vitamina B2 $12 \mathrm{mg}$, Vitamina B6 $6 \mathrm{mg}$, Vitamina B12 0,02 mg, Ácido Fólico $3 \mathrm{mg}$, Ácido Nicotínico $70 \mathrm{mg}$, Ácido Pantotênico $25 \mathrm{mg}$, Biotina 0,40 mg, Antioxidante $88 \mathrm{mg}$. 
Tabela 1.3 Composição das dietas experimentais no período de 85 a 112 dias. (85 a 112 dias).

\begin{tabular}{|c|c|c|c|}
\hline Ingredientes & T1 & $\mathrm{T} 2$ & T3 \\
\hline Milho & 51,83 & 51,20 & 51,20 \\
\hline Farelo de Soja $46 \%$ & 30,10 & 30,20 & 30,20 \\
\hline Trigo & 8,00 & 8,00 & 8,00 \\
\hline Fosfato Monobicálcico 20\% & 1,86 & 1,86 & 1,86 \\
\hline Óleo de Soja Degomado & 5,30 & 3,80 & 3,80 \\
\hline Caulim & - & 2,00 & 1,99 \\
\hline Calcário Calcítico & 1,61 & 1,64 & 1,64 \\
\hline Metionina Hidróxi Análoga & 0,16 & 0,16 & 0,16 \\
\hline L-Lisina & 0,28 & 0,28 & 0,28 \\
\hline Sal Moído & 0,25 & 0,25 & 0,25 \\
\hline Bicarbonato de Sódio & 0,15 & 0,15 & 0,15 \\
\hline Premix Mineral $^{\mathrm{a}}$ & 0,10 & 0,10 & 0,10 \\
\hline Premix Vitamínico ${ }^{\mathrm{b}}$ & 0,10 & 0,10 & 0,10 \\
\hline L-Treonina $98,5 \%$ & 0,11 & 0,11 & 0,11 \\
\hline Cloreto de Colina 60\% & 0,03 & 0,03 & 0,03 \\
\hline Xilanase & - & - & 0,01 \\
\hline Níveis Nutricionais Calculados & T1 & T2 & T3 \\
\hline Proteína Bruta & 20,00 & 20,00 & 20,00 \\
\hline $\mathrm{Ca}$ & 1,00 & 1,04 & 1,04 \\
\hline P Disponível & 0,45 & 0,45 & 0,45 \\
\hline Lisina (dig) & 1,07 & 0,90 & 0,90 \\
\hline Metionina (dig) & 0,47 & 0,47 & 0,47 \\
\hline Metionina + Cistina (dig) & 0,64 & 0,64 & 0,64 \\
\hline Treonina (dig) & 0,70 & 0,70 & 0,70 \\
\hline Triptofano (dig) & 0,19 & 0,19 & 0,19 \\
\hline Energia Metabolizável (kcal/kg) & 3.200 & 3.050 & 3.050 \\
\hline
\end{tabular}

${ }^{\mathrm{a}}$ Fornecido por kg de ração: Cobre $20 \mathrm{mg}$, Ferro $50 \mathrm{mg}$, Manganês $115 \mathrm{mg}$, Zinco $100 \mathrm{mg}$, lodo 2 mg, Selênio $0,35 \mathrm{mg}$. ${ }^{b}$ Fornecido por kg de ração: Vitamina A $10.500 \mathrm{UI}$, Vitamina D3 $3.500 \mathrm{UI}$, Vitamina E $52 \mathrm{mg}$, Vitamina K $4 \mathrm{mg}$, Vitamina B1 $3 \mathrm{mg}$, Vitamina B2 $9 \mathrm{mg}$, Vitamina B6 $9 \mathrm{mg}$, Vitamina B12 0,015 mg, Ácido Fólico $2 \mathrm{mg}$, Ácido Nicotínico $52 \mathrm{mg}$, Ácido Pantotênico $19 \mathrm{mg}$, Biotina $0,30 \mathrm{mg}$, Antioxidante $88 \mathrm{mg}$. 
Tabela 1.4 Composição das dietas experimentais no período de 113 a 126 dias.

\begin{tabular}{|c|c|c|c|}
\hline Ingredientes & T1 & T2 & T3 \\
\hline Milho & 56,81 & 56,18 & 56,18 \\
\hline Farelo de Soja $46 \%$ & 25,70 & 25,80 & 25,80 \\
\hline Trigo & 8,00 & 8,00 & 8,00 \\
\hline Fosfato Monobicálcico 20\% & 1,90 & 1,90 & 1,90 \\
\hline Óleo de Soja Degomado & 5,00 & 3,50 & 3,50 \\
\hline Caulim & - & 2,00 & 1,99 \\
\hline Calcário Calcítico & 1,64 & 1,67 & 1,67 \\
\hline Metionina Hidróxi Análoga & 0,14 & 0,14 & 0,14 \\
\hline L-Lisina & 0,18 & 0,18 & 0,18 \\
\hline Sal Moído & 0,35 & 0,35 & 0,35 \\
\hline Premix Mineral $^{a}$ & 0,10 & 0,10 & 0,10 \\
\hline Premix Vitamínico ${ }^{b}$ & 0,10 & 0,10 & 0,10 \\
\hline L-Treonina 98,5\% & 0,05 & 0,05 & 0,05 \\
\hline Cloreto de Colina $60 \%$ & 0,03 & 0,03 & 0,03 \\
\hline Xilanase & - & - & 0,01 \\
\hline Níveis Nutricionais Calculados & T1 & T2 & T3 \\
\hline Proteína Bruta & 18,00 & 18,00 & 18,00 \\
\hline $\mathrm{Ca}$ & 1,04 & 1,04 & 1,04 \\
\hline P Disponível & 0,45 & 0,45 & 0,45 \\
\hline Lisina (dig) & 0,90 & 0,90 & 0,90 \\
\hline Metionina (dig) & 0,47 & 0,47 & 0,47 \\
\hline Metionina + Cistina (dig) & 0,64 & 0,64 & 0,64 \\
\hline Treonina (dig) & 0,70 & 0,70 & 0,70 \\
\hline Triptofano (dig) & 0,19 & 0,19 & 0,19 \\
\hline Energia Metabolizável (kcal/kg) & 3.220 & 3.070 & 3.070 \\
\hline
\end{tabular}

${ }^{a}$ Fornecido por kg de ração: Cobre $20 \mathrm{mg}$. Ferro $50 \mathrm{mg}$, Manganês $115 \mathrm{mg}$, Zinco $100 \mathrm{mg}$, lodo $2 \mathrm{mg}$, Selênio $0,35 \mathrm{mg}$. 'Fornecido por kg de ração: Vitamina A $10.500 \mathrm{UI}$, Vitamina D3 $3.500 \mathrm{UI}$, Vitamina E $52 \mathrm{mg}$, Vitamina K $4 \mathrm{mg}$, Vitamina B1 $3 \mathrm{mg}$, Vitamina B2 $9 \mathrm{mg}$, Vitamina B6 $9 \mathrm{mg}$, Vitamina B12 0,015 mg, Ácido Fólico $2 \mathrm{mg}$, Ácido Nicotínico $52 \mathrm{mg}$, Ácido Pantotênico $19 \mathrm{mg}$, Biotina $0,30 \mathrm{mg}$, Antioxidante $88 \mathrm{mg}$. 


\section{RESULTADOS E DISCUSSÃO}

Os resultados do consumo de ração, ganho de peso e conversão alimentar foram apresentados nas tabelas 2, 3 e 4, respectivamente.

A diferença significativa no consumo de ração $(P<0,05)$, comparando a dieta controle com os demais tratamentos, foi resultado da diferença de energia entre os tratamentos e a grande habilidade das aves em regular o consumo, a fim de manter seu crescimento, à semelhança ao que Lesson et al. (1996) constataram. Bertechini (1987), comentou que as aves tendem a diminuir o consumo de ração quando os níveis energéticos são maiores em função do controle de ingestão de calorias.

Tabela 2. Consumo de ração $(\mathrm{kg})$ de peruas de corte, em fases, aos 56, 84, $112 \mathrm{e}$ 126 dias de idade.

\begin{tabular}{cccccc}
\hline Tratamentos & $\mathbf{2 9}$ a $\mathbf{5 6}$ & $\mathbf{5 7}$ a $\mathbf{8 4}$ & $\mathbf{8 5}$ a $\mathbf{1 1 2}$ & $\mathbf{1 1 3}$ a $\mathbf{1 2 6}$ & $\mathbf{2 9}$ a $\mathbf{1 2 6}$ \\
\hline 1 & $4,9 \mathrm{~b}$ & $10,3 \mathrm{~b}$ & $17,5 \mathrm{~b}$ & 6,7 & $39,4 \mathrm{c}$ \\
2 & $5,0 \mathrm{a}$ & $10,8 \mathrm{a}$ & $19,2 \mathrm{a}$ & 7,2 & $42,2 \mathrm{a}$ \\
3 & $5,1 \mathrm{a}$ & $10,6 \mathrm{ab}$ & $18,5 \mathrm{a}$ & 6,8 & $41,0 \mathrm{~b}$ \\
\hline Valor de P & 0,015 & 0,050 & 0,004 & 0,261 & 0,001 \\
CV (\%) & 2,387 & 3,919 & 4,633 & 9,140 & 2,382 \\
\hline
\end{tabular}

Médias seguidas por letras minúsculas distintas, na mesma coluna, diferem entre si pelo teste de Duncan (5\%).

A diferença significativa $(P<0,05)$ no consumo de ração no período de 29 a 126 dias entre o tratamento 2 - dieta controle com redução de $150 \mathrm{kcal}$ e o tratamento 3 - dieta controle com redução de 150 kcal e adição de xilanase, pode ser explicada pela diminuição da viscosidade da dieta, provocada pela ação da enzima xilanase nas dietas formuladas com trigo (Brenes et al., 1993) a partir do $57^{\circ}$ dia de vida.

No primeiro período, entre o $29^{\circ} \mathrm{e}$ - $56^{\circ}$ dia de vida, a inclusão da xilanase na dieta formulada a base de milho e farelo de soja não resultou em diferenças significativas de consumo. Este resultado pode ser explicado pela pequena presença de substrato para a ação da enzima na ração, não melhorando então a energia metabolizável da dieta. Possivelmente, houve o efeito da enzima xilanase apenas sobre alimentos com alta concentração de polissacarídeos não amiláceos, com predominância de arabinoxilanos (Conte, 2002).
Juin (1997), avaliando dietas a base de trigo e farelo de soja, verificou um incremento de $95 \mathrm{kcal} / \mathrm{kg}$ de energia metabolizável na $13^{\mathrm{a}}$ semana de vida de perus. De maneira semelhante, Conte (2000), em estudo do efeito da xilanase sobre a energia metabolizável da ração com $15 \%$ de farelo de arroz, suplementada com fitase e xilanase, demonstrou $\mathrm{o}$ efeito positivo da xilanase, com uma melhora média de $8 \%$ na energia metabolizável. Ao avaliar o trigo e a cevada Rodehutscord (2007) obteve uma melhora na energia metabolizável de $6 \%$.

A diferença no nível de energia entre os tratamentos não interferiu para o ganho de peso $(P>0,05)$, mesmo com as dietas seguindo as recomendações da linhagem. Isso foi encontrado também por Bacon et al. (1981), Reece e McNaugton (1982), Lesson et al. (1996) e Lecznieski et al. (2001), em pesquisas com frangos de corte. Já Pesti e Fletcher (1983), ao contrário, verificaram melhoria no ganho de peso 
elevando-se a energia para frangos de corte na fase de crescimento.

A inclusão da enzima xilanase não resultou em diferenças significativas $(P>0,05)$ sobre o ganho de peso. Esse resultado apresentou-se diferente daqueles encontrados por Heindl e
Steenfeldt (1999), que, trabalhando com dietas contendo $45 \%$ de trigo e adicionando 100 ppm de xilanase, tiveram o ganho de peso melhorado em $7,3 \%$ durante o período de 0 a 42 dias em frangos de corte.

Tabela 3. Ganho de peso $(\mathrm{kg})$ de peruas de corte, em fases, aos 56, 84, 112 e 126 dias de idade.

\begin{tabular}{cccccc}
\hline Tratamentos & $\mathbf{2 9}$ a 56 & $\mathbf{5 7}$ a $\mathbf{8 4}$ & $\mathbf{8 5}$ a 112 & $\mathbf{1 1 3}$ a 126 & $\mathbf{2 9}$ a 126 \\
\hline 1 & 3,1 & 5,2 & 5,3 & 2,5 & 16,2 \\
2 & 3,2 & 5,3 & 5,2 & 2,6 & 16,4 \\
3 & 3,2 & 5,3 & 5,3 & 2,5 & 16,3 \\
\hline Valor de P & 0,071 & $\mathrm{~ns}$ & $\mathrm{~ns}$ & $\mathrm{~ns}$ & $\mathrm{~ns}$ \\
CV (\%) & 3,274 & 3,011 & 3,941 & 8,457 & 1,705 \\
\hline
\end{tabular}

A utilização da enzima xilanase poderia ter uma melhor resposta sobre o ganho de peso, caso as dietas experimentais tivessem uma maior inclusão de trigo. Rodehutscord (2007) observou um significativo $(\mathrm{P}<0,05)$ ganho de peso na $16^{\text {a }}$ semana de vida de perus em dietas que tiveram uma inclusão de $60 \%$ de trigo. Neste mesmo experimento, o consumo diário de ração foi reduzido $(P<0,05)$ em $7 \mathrm{~g}$ por dia, o que resultou numa conversão alimentar menor $(P<0,01)$ em 10 pontos.

Tabela 4. Conversão alimentar $(\mathrm{kg})$ de peruas de corte, em fases, aos $56,84,112$ e 126 dias de idade.

\begin{tabular}{cccccc}
\hline Tratamentos & $\mathbf{2 9}$ a 56 & $\mathbf{5 7}$ a $\mathbf{8 4}$ & $\mathbf{8 5}$ a 112 & $\mathbf{1 1 3}$ a 126 & 29 a 126 \\
\hline 1 & 1,574 & 1,974 & $3,275 \mathrm{~b}$ & 2,608 & $2,406 \mathrm{c}$ \\
2 & 1,569 & 2,035 & $3,661 \mathrm{a}$ & 2,787 & $2,549 \mathrm{a}$ \\
3 & 1,571 & 1,972 & $3,508 \mathrm{ab}$ & 2,730 & $2,486 \mathrm{~b}$ \\
\hline Valor de P & $\mathrm{ns}$ & 0,349 & 0,011 & $\mathrm{~ns}$ & 0,001 \\
CV (\%) & 2,255 & 4,786 & 6,624 & 11,170 & 1,735 \\
\hline
\end{tabular}

Médias seguidas por letras minúsculas distintas, na mesma coluna, diferem entre si pelo teste de Duncan (5\%).

Ocorreram diferenças significativas $(P<0,05)$ na conversão alimentar entre os tratamentos. A melhor conversão alimentar do tratamento 1 pode ser resultado do maior nível de energia da dieta. Vieira et al. (2002) estudaram duas fontes de óleos para frangos de corte, concluíram que conforme aumentava a proporção de gordura na ração, ocorria uma melhora na conversão alimentar. O mesmo foi observado por Benício et al. (1995), que obtiveram uma melhora na conversão alimentar das aves quando elevaram os níveis de Energia Metabolizável da ração.

No tratamento 3 , com redução de 150 kcal e inclusão da enzima xilanase, a conversão alimentar foi significativamente melhor $(P<0,05)$ do que no tratamento 2 , essa melhora ocorreu a partir das fases onde houve uma maior inclusão de trigo nas dietas. O estudo de Veldmann e Vahl (1994) 
mostrou que a diminuição na viscosidade das dietas faz com que a conversão alimentar melhore.

Esta melhoria foi encontrada também por Boguhn (2002), onde a enzima exógena xilanase melhorou a conversão alimentar quando suplementadas em uma dieta formulada a base de trigo para perus, principalmente no segundo período de crescimento. Mathlouthi et al. (2003) avaliaram a eficiência da mistura das enzimas xilanase e $\beta$-glucanase em dois experimentos com perus na fase de crescimento, oferecendo dieta à base de trigo ou trigo e cevada, concluíram que a combinação das duas enzimas melhorou significativamente o ganho de peso e a conversão alimentar no mesmo experimento.

Comparando-se o tratamento 2 e 3 a melhoria na conversão alimentar foi de $2,5 \%$, o que confirmou os resultados encontrados por $\mathrm{Wu}$ e Ravindran (2004), que, trabalhando com dietas à base de farinha de trigo e trigo integral, encontraram benefícios da suplementação com xilanase na conversão alimentar dos frangos, sendo essa melhorada em $2,5 \%$ em relação à dieta sem suplementação.

\section{CONCLUSÕES}

A adição da enzima xilanase em dietas de peruas, formuladas a base de milho e farelo de soja, não promoveram melhorias sobre 0 desempenho das aves dos 29 ao 56 dias. Quando o trigo foi utilizado nas dietas com xilanase, verificou-que houve a diminuição no $\mathrm{CR}$ e melhoria na CA. Diante dos resultados verificados, recomenda-se o uso suplementar da xilanase em dietas ricas com PNAs, tais como àquelas com trigo para perus fêmeas de 57 até 126 dias de idade em condições criatórias similares a estudada.

\section{REFERÊNCIAS}

ABPA. Relatório anual 2020. Associação Brasileira de Proteína Animal, p.92, 2020.

ANNISON, G.; CHOCT, M. Anti-nutritive activities of cereal non starch polysaccharides in broiler diets and strategies minimizing theirs effects. World's Poultry Science Journal, v.47, p.232-242, 1991.

BACON, W.L.; CANTOR, A.H.; COLEMAN, M.A. Effect of dietary environmental temperature, and sex of marker broilers on lipoprotein composition. Poultry Science, v.60, p.1282-1286, 1981.

BEDFORD, M.R. The effect of enzymes on digestion. Journal of Applied Poultry Science Athens, v.5, n.4, p.370-378, 1996.

BENÍCIO, L.A.S.; ROSTAGNO, H.S.; FONSECA, J.B. Desempenho, rendimento de carcaça e avaliação econômica de diferentes linhagens comerciais de frangos de corte. In.: Conferência Apinco de Ciência e Tecnologia Avícola., Anais: FACTA, 1995.

BERTECHINI, A.G. Efeitos de programas de alimentação, níveis de energia, forma física da ração e temperatura ambiente sobre 0 desempenho e custo por unidade de ganho de peso em frango de corte. Tese (Doutorado) Universidade Federal de Viçosa, 1987, 207f.

BOGUHN, J.; TIMMLER, R.; BRAU, J.; RODEHUTSCORD, $M$. Effect of exogenous endoxylanase on growth and feed conversion in turkeys fed on wheatbased diets. Arch. Geflügelk, v.66, n.4, p.151-157, 2002.

BRENES, A. ; MARQUARDT, R. R. ; GUENTER, W. ; ROTTER, B. A. Effect of enzyme supplementation on the nutritional value of raw, autoclaved, and dehulled lupins (Lupinus albus) in chicken 
diets. Poultry Science, 72 (12): 22812293, 1993.

CONTE, A.J. Valor nutritivo do farelo de arroz em dietas para frangos de corte, com utilização das enzimas fitase e xilanase. Tese (Doutorado) Universidade Federal de Lavras. 2000, $151 f$.

CONTE, A.J. Efeito da fitase e xilanase sobre a energia metabolizável do farelo de arroz integral em frangos de corte. Ciência Agrotecnológica, Lavras, v.26, n.6, p.1289-1296, 2002.

HEINDL, U.; STEENFELDT, S. Australian Poultry Science Symposium,1999.

HEW, L.I.; RAVIDRAN, V.; MOLLAH, Y. et al. Influence of exogenous xylanase supplementation on apparent metabolisable energy and amino acid digestibility in wheat for broiler chickens. Animal Feed Science Technology, v.75, p.83-92, 1998.

JUIN, H. ECONASE XT improves performance in turkey wheat-based diets. Trial Reports, 2007.

LECZNIESKI, J.L.; RIBEIRO, A.M.L.; KESSLER, A.M. et al. Influência da forma física e do nível de energia da ração no desempenho e na composição de frangos de corte. Archivos Latinoamericanos de Nutrición, v.9, n.1, p.6-11, 2001.

MATHLOUTHI, N.; JUIN, H.; LARBIER, $M$. Effect of xylanase and $\beta$-glucanase supplementation of wheat or wheat and barley based dietas on the performance of male turkeys. British Poultry Science, v.44, n.2, p.291-298, 2003.

PERSIA, M.E.; DEHORITY, B.A.; LILBURN, M.S. The effects of enzyme supplementation of corn and wheatbased diets on nutrient digestion and cecal microbial populations in turkeys. The Journal of Applied Poultry Research, v.11, p.134-145, 2004.
PESTI, G.M.; FLETCHER, D.L. The response of male broiler chickens to diets with various protein and energy contents during the growing phase. British Poultry Science, v.24, n.1, p.91-99, 1983.

POURREZA, J.; SAMIE, A.H.; ROWGHANI, E. Effect of supplemental enzyme on nutrient digestibility and performance of broiler chicks fed on diets containing triticale. The Journal of Poultry Science, v.6, n.2, p.115-117, 2007.

REECE, F.N.; MCNAUGHTON, J.L. Effects of dietary nutrient density $\mathrm{O}$ broiler performance at low moderate environment temperatures. The Journal of Poultry Science, v.61, p.2208-2211, 1982.

RODEHUTSCORD, M. ECONASE XT improves performance in turkey wheatbased diets. Trial Reports, 2007.

SAEG, Sistema para Análises Estatísticas, Versão 9.1: Fundação Arthur Bernardes - UFV - Viçosa, 2007.

SANTOS JR, A.A; FERKET, P.R.; GRIME, J.L.; EDENS, F.W. Dietary supplementation fo endoxylanase and phospholipase for turkeys fed wheatbased rations. The Journal of Poultry Science, v.3, p.20-32, 2004.

SILVA, S.S.P.; SMITHARD, R.R. Effect of enzyme supplementation of a ryebased diet on xylanase activity in the small intestine of broilers, on intestinal crypt cell proliferation and on nutrient digestibility and growth performance of the birds. British Poultry Science. v.43, p.274-282, 2002.

TAVERNARI, F.C.; CARVALHO, T.A.; ASSIS, A.P. et al. Polissacarídeo não amiláceo solúvel na dieta de suínos e aves. Revista Eletrônica Nutritime, v.5, n.5, p.673-689, 2008.

TUFARELLI, $\quad$ V.; DARIO, M.; LAUDADIO, $V$. Effect of xylanase 
supplementation and particle-size on performance of guinea fowl broilers fed wheat-based diets. The Journal of

Poultry Science, v.6, n.4, p.302-307, 2007.

VELDMANN, A; VAHL, H.V. Xylanase in broiler diets with differences in characteristics and content of wheat. British Poultry Science. v.35, p.537550, 1994.

VIEIRA, S.L.; RIBEIRO, A.M.L.; KESSLER, A.M. et al. Utilização da energia de dietas para frangos de corte formuladas com óleo ácido de soja. Revista Brasileira de Ciência Avícola, v.4, n.2, 2002.

WARD, N.E. With dietary modifications, wheat can be used for poultry. Feedstuffs, v.67, n.33, p.14-15, 1995.

WU, Y.B.; RAVIDRAN, V. Influence of whole wheat inclusion and xylanase supplementation on the performance, digestive tract measurements and carcass characteristics of broiler chickens. Animal Feed Science Technology, v.116, p.129-139, 2004. 